\title{
Induced Microseismicity due to Raising Mine Water Level in Former Coal Mines in the Eastern Ruhr Area (Germany)
}

Martina Rische (martina.rische@rub.de), Kasper D.Fischer, Wolfgang Friederich Institute of Geology, Mineralogy and Geophysics, Ruhr-University Bochum

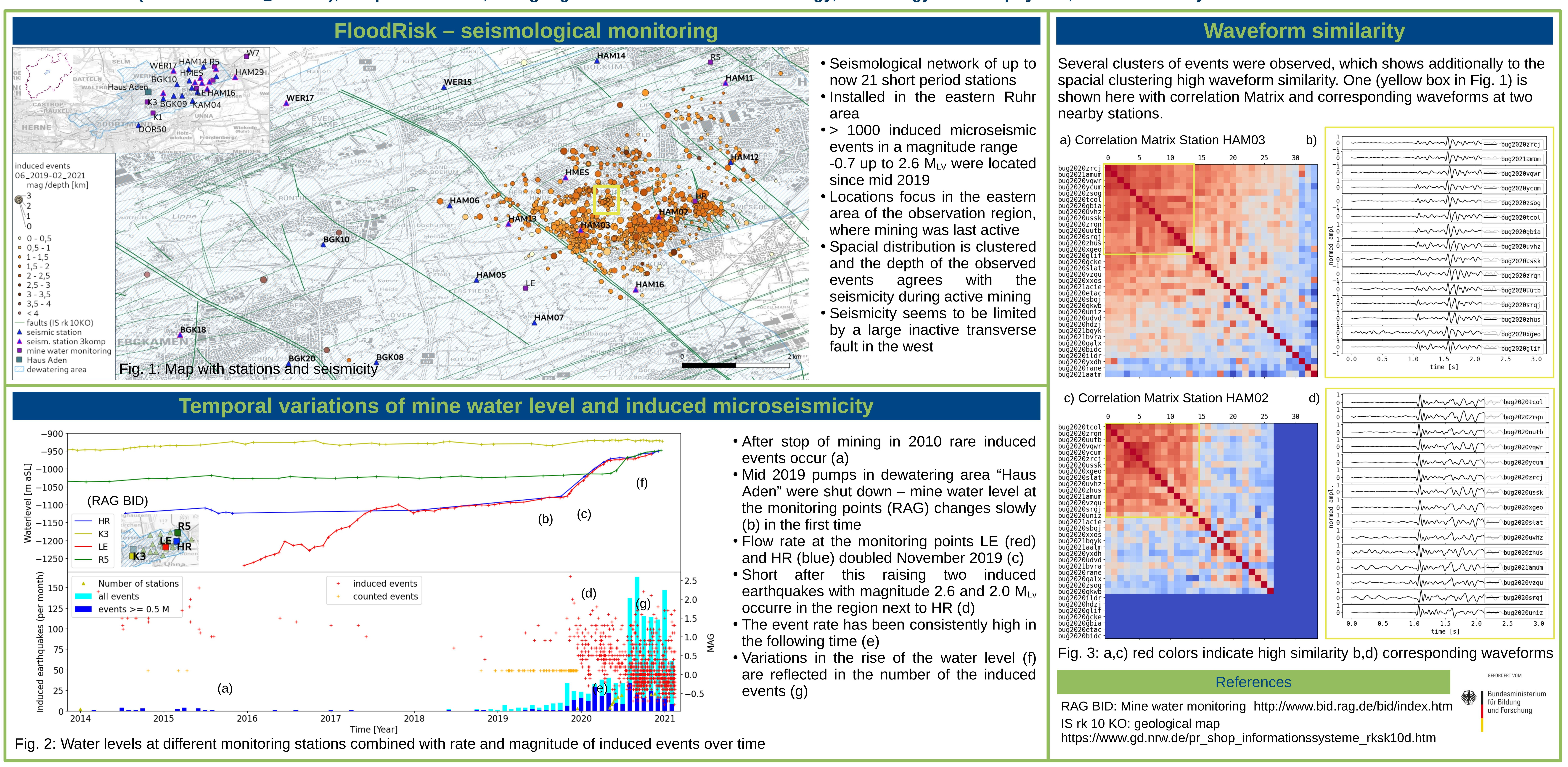

